\title{
Stepping between different worlds: reflections before, during and after fieldwork.
}

\author{
Giovanna Bacchiddu (Department of Anthropology, University of St \\ Andrews)
}

Before beginning fieldwork, the anthropology student pictures herself in a totally different dimension: an 'indigenous' world in which she will be immersed for the whole fieldwork period: she does not know the native language, she has no idea of who she will meet or where she will spend most of her time. Then, the 'limbo' state ends and she finds herself suddenly active, even when she does nothing. To be doing fieldwork means to be constantly observed by other people as well as having to observe all around oneself.

This paper explores issues I lived through and experienced before, during and after my fieldwork in southern Chile. It is a personal narrative of the contradictions that the fieldworker frequently has to face - especially when doing research in a region that has never been studied by anthropologists before. In it I discuss some of the most confusing episodes that occurred to me during my process of becoming familiar with the host culture. These events illustrate the difficulty of overcoming the 'innocence' typical of the inexperienced fieldworker and the impossibility of stepping outside one's own cultural expectations, despite months of serious professional training.

Eventually the experience of fieldwork deeply transforms the fieldworker and her perceptions both of herself and the surrounding world. However, can we cope with the potentially dangerous underpinnings of adopting a different lifestyle for a long period of time? Fieldwork provides us with a chance (with all its emotional implications) to step from one world to another, and the feeling of belonging to both worlds - despite the enormous distance between them.

\section{Stepping between different worlds}

When I was about to leave for my fieldwork, I remember a strange conversation one of my supervisors was having, somewhat jokingly, with another person in the school lift. He was saying: 'We anthropologists are truly different, we are the only ones who send our students out and we don't even know if they will ever come back!' I remember that I stared at him puzzled, but he disappeared, leaving me to wonder about the empty spaces that were awaiting me-and at that time I felt more at ease within the small, familiar space of the lift. My feeling of being lost was heightened further by the fact that no anthropologist had previously carried out fieldwork in the area I was planning to study. This meant that there was neither any generic nor specific information available, and consequently there existed no reassuring survival strategies I could rely on. I only had the various fieldwork anecdotes I had heard from fellow students and teachers to go by. 
In this paper I explore some of the contradictions of fieldwork, as I experienced them before, during and after my time as a fieldworker in southern Chile. Does fieldwork make any sense at all? Are we working and going through extremes of pain and joy for the sake of research, or merely to fulfil our egos (cf. Barley 1983)? And what about the people we study? Will they ever benefit from our engagement with them? Lastly, how do we cope with ourselves in the fieldwork situation, not only as human beings, but also as anthropologists, given that we will find ourselves emotionally involved to a degree that can be overwhelming?

In considering these issues, I follow Dwyer, who argued that it is fundamental, in ethnographic writing, to 'confront rather than disguise the vulnerability of the Self and its society in the encounter with the Other' (1982: xxii).

\section{Before}

We know that fieldwork is a rite de passage that awaits every trainee anthropologist, the essential stage to pass through in order to join the ranks of those who have already experienced 'the real thing'. As a student I used to listen, with admiration and envy, to the fascinating stories of teachers and fellow students who had just returned from the field. 'I used to live in a place about five hours away by motorbike from the first village', a friend told me. 'And how did you manage?' I asked, horrified. 'I bought myself a motorbike!' she replied, smiling. Some fellow post-graduates came back plump and fat, others had lost weight, sometimes up to ten kilos. Some had learned really complicated languages; others had to rely on a field assistant in order to communicate. Some had learned hunting and fishing techniques while others had been scuba diving or had learned how to weave baskets.

I was fascinated by the stories of academics who would temporarily abandon their familiar environment, their comfortable homes, and their families to go off into the middle of the jungle, hours and hours away from healthcare, and willingly expose themselves to diverse dangers for the sake of research. I was struck by the ease and the naturalness with which they seemed to switch between two different realities. I remember I had lots of questions to ask those I considered the privileged ones, who appeared so heroic to me. I wanted to know about the practical details, as well as more serious matters such as the profound problems of communication between the European student and the people they met during fieldwork. What about the clash of cultural values and attitudes? How can you possibly manage, if you can hardly speak the language and no one tells you what you should and should not do?

Then I went on a short preliminary field trip, to check, rather presumptuously, if this landscape and these people were suitable for me and my research. When I was there I was very active: I observed attentively, I asked direct questions and I tried to engage people in conversation on what I assumed to be crucial topics. Later I realized that I made several mistakes - and now that I know much more about my field hosts I realise how insensitive and intrusive I had been. In these situations one becomes starkly aware of the differences between 'us' and 'them'. In the field we are driven by the urge to gather data, to collect 'cultural facts' to feel that we have accomplished something, to feel productive. We are tremendously aware of the passing of time, and each minute we spend in the field must lead on to something. I remember my apprehension at the prospect of spending hour after hour sitting behind a stove, in the company of silent people, for 18 long months, and feeling frustrated at not being able 
to gather useful, clear and straightforward information. My line of reasoning was: 'I am a student, I am here for research, and I need to make the best of the time I am going to spend here'. This is a line of reasoning that is possibly familiar to many firsttime fieldworkers.

With the 'package of information' I had gathered during my short pre-fieldwork trip, and with a rough idea of what I wanted to research I proceeded to write my research proposal, which had to be original, informed by a pertinent theory, academically feasible, and practically do-able. A difficult challenge, for we have to imagine situations that we do not really know, and question other anthropologists' theories and their relevance to our fieldsite. We are required to pretend that we know a lot, while in fact the very opposite is true-and, incidentally, this is the reason behind wanting to do fieldwork!

When the long awaited moment came, the practicalities of packing whatever was necessary for a two-year trip somehow distracted me from the crazy adventure on which I was about to embark. It was only when I was already on the plane, flying across the Atlantic ocean, that reality suddenly hit me and I realized-almost panicking - that there I was, heading towards the unknown.

\section{During}

After so much fantasizing about what my life would be like in a different and unknown country, I finally arrived in Santiago de Chile. It was late November, in the middle of the summer, 35 degrees, and the parents of a Chilean friend were waiting for me at the airport. My hosts were talking to me in such a warm and caring manner that I felt immediately connected and welcome. The familiarity with which I was treated and the warmth of their hospitality made my arrival incredibly pleasant. I felt loved, appreciated and admired for the sole reason of being there, away from my family and about to start an adventure that seemed daunting even to my hosts.

After having become familiar with the language and feeling reasonably at ease with the fact of being in Chile, I had to move towards the country's periphery, more than a thousand kilometres from the capital, and find a fieldsite. Given that I had no

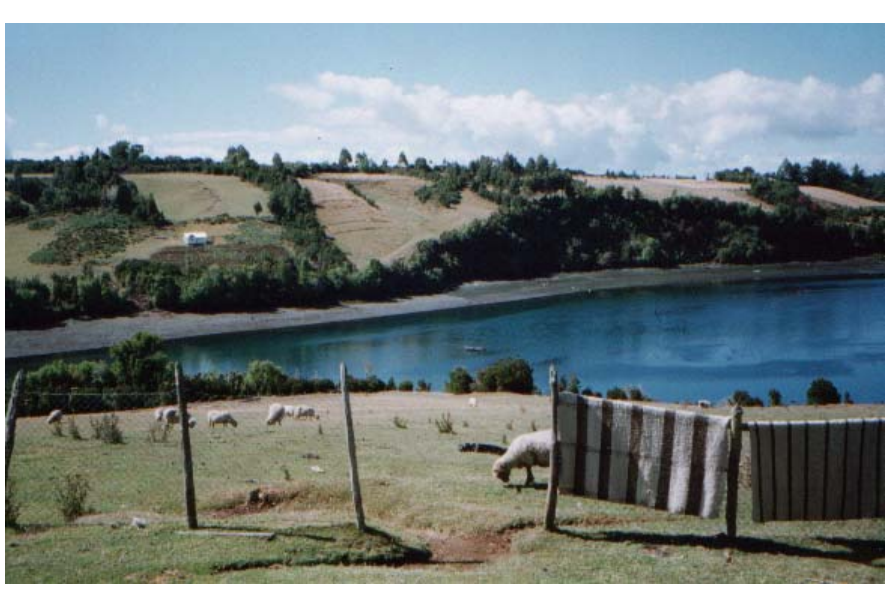

Figure 1: A sunny day on the island. contact in that area at all, I had to find someone who could provide useful suggestions about a place to stay for my research. After a long and boring series of adventures, I finally settled on a small island with 700 inhabitants, three to four hours away from a small town.

The fact that I was living on an island somehow intensified the sense of separation and isolation from my previous world. There was no electricity, no phone, no computers and obviously no email, and a boat left the island only twice a weekweather permitting. There was absolutely nothing to do, or so it seemed at the time. It 
was extremely boring. A social life, such as I expected, was non-existent: there were no places for people to meet and socialize; no restaurants or bars, no markets or shops; no public square for people to convene in. Even the church was permanently closed for lack of a priest. To add to the sense of desolation I felt, the weather was terrible. It rained constantly and heavily, while chilly Cordillera winds blew. It was July: just an ordinary winter in southern Chile.

Since there were very few 'public' situations to observe, I concentrated on the 'domestic'. After all, with the torrential rain, people tended to spend most of their time in the house, more specifically in the only heated room: the kitchen. In an attempt to become familiar with my hosts I engaged in conversations, demonstrating

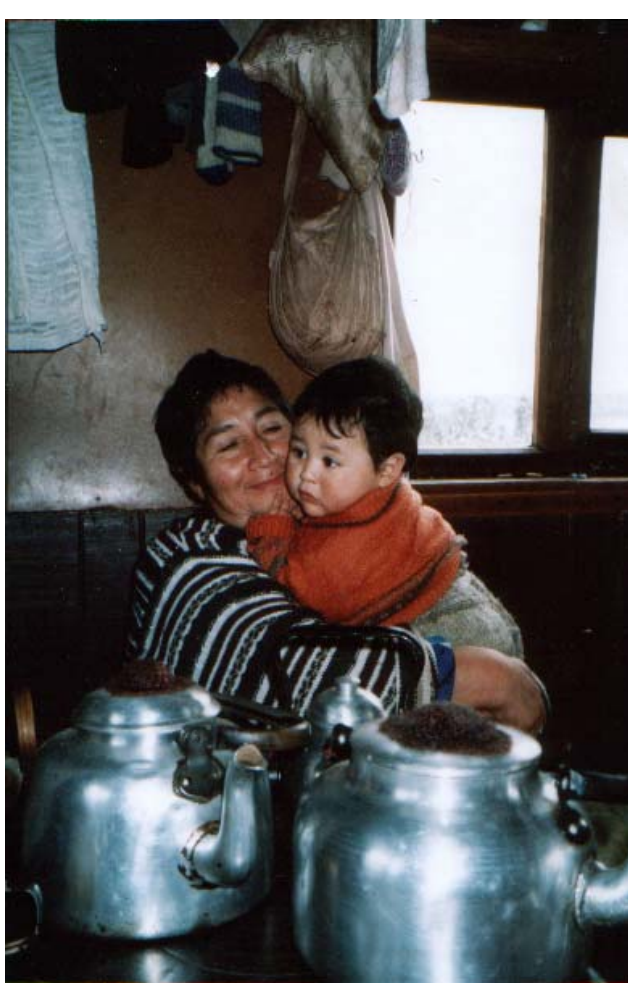

Figure 2: Claudina and her grandson behind the stove. my willingness to get to know them as well as showing them something about myself. I knew that I was a real mystery to them. During the boat trip to the island, people had made a point of staring at me defiantly for the entire journey; yet, no one had said a word to me. I understood my presence could be perceived as threatening. In order to overcome what I felt was an unpleasant sense of difference lurking between us, I decided to demonstrate my harmlessness to the people on the island. I did this by talking a lot, and by sitting close to women-in an attempt to show them my willingness to share my time and to prove I was trustworthy. Unfortunately my attitude provoked very embarrassed reactions: people felt I had invaded their privacy and consequently were even more taciturn than usual, and my attempt at conversation was often met with yawning. Later I learnt that physical proximity does not imply emotional closeness, just as physical distance is not a sign of emotional distance.

Little by little I made some friends and I was welcomed in a warmer way whenever I went visiting. Most of the times I was offered food and drink. Some of the women started to accept me and began talking to me. Then, the same women who had been so friendly and warm when I came to visit, would ignore me on a public path, or in religious meetings - for no apparent reasonif they were with someone else or if I was accompanied. I was puzzled and I felt that I had to start all over again, by slowly building connections, making myself known and appreciated. It was as if all my previous efforts had been completely wiped out. The codes of behaviour that seemed to inform my hosts' lives were really different to what I had expected, and it took me a long while to make sense of them. As Gow has put it, 'ethnographic fieldwork entails, for fieldworkers, an extreme sensitization to the nature of their assumptions about what humans are like, as these are daily brought into conflict with the corresponding assumptions of the people being studied' (Gow 2001: 22). 
I had, in a sense, to 'suspend' all my previous knowledge, all my conscious and unconscious ideas about what was 'common sense', and I had to slowly substitute them with what my hosts took to be common sense. This had to be done in every possible field: from social relations and tastes in music, food and drink, to ideas about what was comfortable, or better. Just like I had to re-learn how to walk-in fact, I had to adapt my taken-for-granted walking ability to a completely different kind of terrain (muddy and very slippery) - I had to re-learn a different way of thinking and behaving. Eventually I became so absorbed by peoples' lives and lived experiences that I genuinely became an active member of the community. I was able to express myself using the regional expressions in the peculiar local accent; I was able to interact with other islanders in their own way, I had internalized their typical gestures and bodily postures. In addition to these embodied aspects of culture, I was increasingly familiar with the 'internal rules' that are hardly voiced because they are taken for granted - the 'back bone' of a culture (see Bloch 1998). The various sequences of some common social and religious events became very familiar to me. All the peculiarities that had surprised me and caught my attention when I had first arrived, were now obvious matters that I could put in context. I felt at ease with most of the people, and certain occurrences hardly surprised me at all. In sum, I had naturally and effectively adopted my hosts' mentality. Or so it seemed to me at the time.

\section{After}

The trouble is that at some point the student has to go back home, and this usually happens when things are going really smoothly, when all the secrets are just being disclosed and when even the most hostile people are becoming more friendly and talkative. The feeling of having to leave a place just when it all starts to make sense is a very common experience among fieldworkers. Moreover, during our time in the field we tend to get attached to some people, and I was no exception. I had grown so close to my host family and friends that the idea of separation seemed unbearable, both for myself and for them. My looming future absence was discussed and commented upon, days and activities without my presence were imagined and talked about, in serious conversation as well as in a joking way, turning pain into laughter. I was particularly sad to leave the old great-grandmother and the children. I thought that I would never find things and people again the way I left them. Still, nothing can be done: visas expire and we have to go back home.

Once back in London, I experienced a sense of intense displacement: an incident of what could be called reverse culture shock. I was totally unprepared for it. Just like I had felt out of context at the beginning of my fieldwork, I was again feeling the same-but this time I was supposedly on familiar ground! The experience was so powerful that I felt paralysed. I was incapable of dealing with the immense crowds that animated the streets, the noise of traffic, the waste of electricity, water and paper. I did not know who I was, where I was, and in what language I was organizing my confused thoughts. I was unable to speak English any longer. It was even worse when, a month later, I went home to Italy: I could not speak Italian either, and I needed to be left in solitude to gather my thoughts. I felt I had lost myself in a world that did not belong to me, and I was unable to find my old self - indeed so much had changed in the meantime; more than anything, I had changed. I also felt the frustration of what seemed the sheer impossibility of communicating my fieldwork experience: an 
experience that belonged only to me and that I felt unable to share. I felt people would not really understand the feelings and emotions involved in what I had lived through.

Now that I am trying to distance myself from my days of fieldwork, in order to read through my data and analyse them properly, I realize how difficult a task this is. We go through quick displacement, compulsory adaptation, and then again redisplacement and re-adaptation in a relatively short period of time - and then, we have to write about all this in an academic way. I am trying to ease my way out of what seems to me an almost unachievable task by thinking of my fieldwork as an ongoing relationship. My fieldwork allowed me to connect with a group of people who have given something to me and at the same time have received something from me. I have also been through the unexpected experience of feeling like 'the different other' in a small world of 'alike people'. My hosts coped with the presence of 'the other' in their small island for 18 months, and together we built up several long, complex and unfinished conversations. The ongoing threads of this two year long dialogue will, hopefully, be unravelled, singled out and brought to the surface in my doctoral thesis.

\section{Conclusion: be one of them? The danger of the 'Zelig effect'}

Ever since Malinowski, we anthropologists have been told that the purpose of fieldwork is precisely to 'go native', to be able to think in the others' own terms - this is the only way to approach and access how people think of themselves. But, is this really possible, or even reasonable? To reflect on the matter I will briefly look back, in retrospect, at what seemed to me the most difficult part of the fieldwork endeavour - the moment when a fieldworker has to step out of what she patiently built over several months.

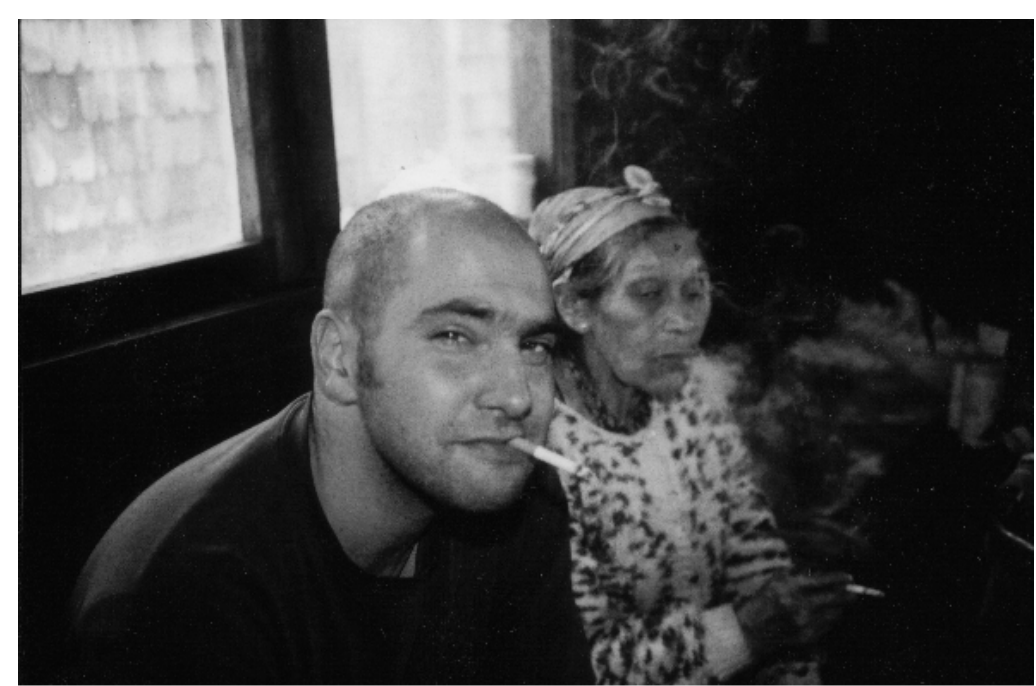

Figure 3: My brother and the great-grandmother Catalina smoking behind the stove.
From a distance, I can clearly visualize myself shortly before I had to leave, and my pain at the prospect made my attachment more intense. One of my brothers had come to visit right on the last week of my stay in the island, and-although incredibly happy to have him there-the timing was quite bad and there seemed to be a gap between us. He was keen on updating me on the political situation of our country, on the last satirical TV programmes that made fun of the government, and he wanted to share his impressions with my fellow island friends too. There he was, speaking half Italian, half Spanish one night on the beach, when we were reunited for a farewell bonfire. I could not help but consider my brother's concerns a thousand miles away from my own - and I felt to be sharing this same feeling with my local friends sitting around the fire. That night I had my two 
worlds in front of me: my 'old' life, personified by my brother, whose visit I had longed for and eagerly awaited for months, and my 'new' world, represented by my island friends to whom I had grown strong feelings of love and attachment. I had pictured this moment many times, and now that it was real something was not working the way I expected: it was as if the two worlds could not easily blend. I wished my brother was more into my 'new' world-but maybe I was expecting too much of him. I understand now that it was impossible for him to share my deepest feelings.

When I left the field a few days later, I felt as if I had been torn from a social and emotional fabric in which I had become perfectly entwined. Where was my old self? Had my fieldwork been too successful in making me part of my hosts' life - so much that through deep understanding and adoption of the same, I had been slowly forgetting my old self? Was my previous culture truly effaced? Or, was I, chameleonlike, able to adapt to a radically different world, and easily switch from one reality to another? My deep involvement with my field world curiously reminds me of Zelig, the chameleon-like character created and portrayed by Woody Allen in the early Eighties (Allen 1983). Zelig is a man with the ability (and the curse) to integrate into any social setting in which he happens to find himself, because of his need to 'fit in'. $\mathrm{He}$ is so desperate to conform and to blend in with the crowd, that he inadvertently starts a physical and emotional transformation. While to assimilate the fieldworker to the grotesque and pathological Zelig character might appear a bit excessive, it is true that this character portrays an aspect quite familiar to the anthropologists' experience. Any anthropologist needs to be accepted by the community-and this implies not only downplaying differences but also engaging in a process of 'imitation'. The desire to feel part of the group and to succeed in creating ties - in order to conduct a successful research-has unexpected emotional consequences. I had experienced the end of my fieldwork period as an abrupt rupture, a too sudden change, which I had no time to come to terms with before it was upon me. I did not feel, as often happens, that it was time to go. While I could have taken my sense of familiarity as a signal and a reminder that my research had reached a satisfactory point of completion and that it was time to move on, instead I dreaded the approaching separation. The sense of confusion and displacement that I experienced in London was probably intensified by this reluctance to accept the end of my Chilean stay. Winter had just finished in Chile, and summer was about to start: I am not really prepared for another hard winter in Europe, I kept thinking.

Seven months after my return, a deus ex machina situation offered me another chance to look into my fieldwork experience somehow through different eyes. I was concentrating on organizing my copious field notes and was beginning my writing, when unexpectedly I was offered the chance to go back to Chile for a conference. My initial reaction was of strong rejection: I was only just emerging from that intense emotional turmoil that had been the separation from my fieldwork. How could I possibly cope with plunging into the same feelings again? And admittedly seven months was just too short a gap to be back to double-check and complete some of my data. I seriously considered not going. Then I eventually, though reluctantly, decided that I could and should make the effort. I planned to extend my stay and return to my field site. Thus I packed my rucksack again for another two months in a very cold Chilean winter.

The sudden temperature change from a record-breaking hot European summer to the freezing Chilean winter (the exact reverse of my first arrival) was all but pleasant; this 
time I was finding it extremely difficult to cope with the cold. Once on the island the joy and happiness of meeting my old friends overcame the irritation of the pestering fleas and the constant rains. I was very happy and relieved, and I again felt completely at home. Indeed, I was surprised by a distinct feeling of belonging there-irrespective of where I chose to live my life. It was as if I had left for the weekend, or for a couple of weeks break. How silly, I thought, to have been pondering and meditating and missing these people and fearing that God knows what would have irremediably changed during my absence. Seven months after my departure and we had our same clothes on, I was surprisingly able to remember everybody's names and with a click I felt I had once again become a part of the human landscape as if I had never left.

When it was time to leave though, none of us felt the intense pain of our first separation. Then everybody had cried, including some adult men. The overwhelming emotions that followed my first departure had somehow blurred: this time a friend told me with a serene expression: 'Now I know that just as you came back once, you will come back again'. She put in simple words a peculiar feeling of acknowledgement that after all our different worlds were not that distant. The feeling of old and safe familiarity that both me and my hosts experienced assured us that we had been able to build durable ties.

This second fieldtrip allowed me to step back from fieldwork as emotional experience, and to situate everything in the context of my doctoral thesis. While this was certainly not a secondary motivation throughout my time in Chile (to the point that my hosts kept asking me information on my studies and my degree), the emotional underpinnings of the relations I had formed had a privileged place and they had somehow obscured my wider goals. I know that this is, again, a common experience among anthropologists. Siskind for example, describes very similar feelings, talks of the 'romance of fieldwork' and admits she seriously considered never leaving (1973: 19).

Recently, for the purpose of doing some anthropological writing I have focused on what intrigued me most at the very beginning of my fieldwork. In looking at my first impressions of what I found striking about my hosts' perceptions and attitudes towards sociality, I analysed our intrinsic differences in assumptions about everyday concerns. While doing so, I became more aware of the necessary change I went through since I have been back: from a confused and 'romantic' attitude towards what seemed irremediably lost upon completion of fieldwork, to the intellectual distance that enabled me to look at my data in all its richness. The shift was crucial in that I was reminded of the fresh gaze I had when I first arrived in my field-and my ignorance of what was going on was precisely what lay at the root of my data gathering.

Observing my fieldwork experience from these two vantage points highlights its useful extremes: from a state of ignorance of what to expect at the very beginning to a state of emotional involvement towards the end. As anthropologists, our initial ignorance implies a freshness of gaze, attuned to what is different and hence particularly sensible towards facts that eventually become data. In contrast, the close involvement with people who are much more than just 'informants' makes us less likely to 'observe', and more inclined to 'participate'.

Knowing a lot, though, does not make natives of us: paraphrasing Lévi-Strauss (1968: 16) it could be said that just as the best ethnographic study could not transform those 
who read it into indigenous people, the best fieldwork will not turn the ethnographer into an indigenous person. Once back for good, and very involved in the task of analysing my data, I realise that I have gained the knowledge and the experience to feel at home in southern Chile, together with the awareness that my position is and will always be that of a guest, who originally settled there on a fact finding journey. From the point of view of a young anthropologist who is still making sense of her data and the overall field experience, I can say that the only way I can conceive of ethnography (or, more precisely, of $m y$ ethnography) is to constantly evoke the dialogical form of each episode that formed my fieldwork life.

\section{References}

Allen, W. 1983. Zelig. DuArt Film Laboratories Inc., New York, USA. Black and white/colour, 79 mins.

Barley, N. 1983. The innocent anthropologist. Notes from a mud hut. London: British Museum Publications.

Bloch, M.E.F. 1998. How we think they think. Anthropological approaches to cognition, memory and literacy. Oxford: Westview Press.

Dwyer, K. 1982. Moroccan dialogues-anthropology in question. The John Hopkins University Press.

Gow, P. 2001. An Amazonian myth and its history. Oxford: Oxford University Press.

Lévi-Strauss, C. 1968. Structural anthropology. New York: Basic Books.

Siskind, J. 1973. To hunt in the morning. Oxford: Oxford University Press.

\section{About the author}

Giovanna Bacchiddu started her postgraduates studies at the Department of Anthropology of the LSE, London, where she did an MSc and began her doctoral research in southern Chile. She subsequently moved to St Andrews University where she is currently completing her $\mathrm{PhD}$ thesis on sociality, kinship and religion among a community of islanders in Chiloé, southern Chile.

Email: g.bacchiddu@st-andrews.ac.uk 